Tohoku J. exp. Med., 1987, 151, 359-362

\title{
Potent Vasoconstrictor Responses to Endogenous Digitalis-Like Factor of Isolated, Perfused Dog Intermediate Auricular Arteries
}

\author{
Shigetoshi Chiba, Miyoko Tsukada, Yoshiniko \\ Katsuyama, ${ }^{*}$ Akimiro Tada ${ }^{*}$ and Hiroshi Zenda* \\ Department of Pharmacology, Shinshu University School of \\ Medicine and *Department of Pharmacy, Shinshu \\ University Hospital, Matsumoto 390
}

\begin{abstract}
Chiba, S., Tsukada, M., Katsuyama, Y., Tada, A. and Zenda, H. Potent Vasoconstrictor Responses to Endogenous Digitalis-Like Factor of Isolated, Perfused Dog Intermediate Auricular Arteries. Tohoku J. exp. Med., 1987, 151 (3), 359-362 - Endogenous digitalis-like factor obtained from urine of hypertensive patients caused a vasoconstriction in a dose-related manner in isolated, perfused dog intermediate auricular arteries. The constriction was not modified by alphaadrenoceptor blockade. —— EDLF ; cannula inserting method ; dog intermediate auricular artery
\end{abstract}

Recently, endogenous digitalis-like factors (EDLFs, materials that cross react in digoxin immunoassays) have been widely reported to be found in dog and human plasma and urine as reviewed by Soldin (1986). EDLF cross reacts with digoxin antibodies, inhibits $\mathrm{Na}^{+}, \mathrm{K}^{+}$-ATPase, and also causes natriuresis and diuresis like atrial natriuretic factors (materials cause natriuresis, diuresis, and drop in blood pressure, but they neither cross react with digoxin antibodies nor inhibit $\mathrm{Na}^{+}, \mathrm{K}^{+}$-ATPase), as reviewed by Palluk et al. (1985). Chakravarty et al. (1984) reported that natriuretic fraction of human urine induced a contraction of the isolated rat anococcygeus muscle as a variety of known agonists including norepinephrine. It has been assumed that EDLF has a vasoconstrictor property (Plunkett et al. 1982 ; Soldin 1986). However, no report is available as to vasoconstrictor action of the natriuretic fraction in isolated vascular muscle preparation. Thus, using recently developed cannula inserting method (Hongo and Chiba 1983) we made an attempt to investigate whether vasoconstriction of isolated vessels would be induced by EDLF obtained from the urine of hypertensive patients.

Received January 21, 1987 ; accepted for publication February 16, 1987. 


\section{Methods}

The urine (18 liters) of 20 hypertensive patients was treated with $1,000 \mathrm{ml}$ of an adsorbant (Amberlite XAD-4) under stirring for $5 \mathrm{hr}$. An adsorbed fraction on the Amberlite XAD-4 was eluted by 5 liters of methanol. After evaporation of methanol, a residue was dissolved in 1.6 liters of $50 \mathrm{mM}$ Tris- $\mathrm{HCl}$ buffer $(\mathrm{pH} 7.4)$. The Tris- $\mathrm{HCl}$ buffer solution was treated with a $200 \mathrm{ml}$ of DEAE-Sephadex A-25 and a filtrate (unadsorbed fraction) was passed through the ODS silica gel column. An adsorbed fraction on the column was eluted with 1.5 liters of methanol, then evaporated methanol to give $4.1 \mathrm{~g}$ of residue. The residue was dissolved in 1 liter of $50 \mathrm{mM}$ phosphate buffer $(\mathrm{pH} 6.8)$ and the solution was treated with a SP-Sephadex C-25 and an unadsorbed fraction was passed through the ODS silica gel column. The adsorbed fraction on the column was eluted with methanol and evaporated methanol to give $3.74 \mathrm{~g}$ of residue. After a filtration of $400 \mathrm{ml}$ of methanol solution of the residue, methanol of the filtrate was evaporated to give an active fraction. The active fraction was dissolved in $720 \mathrm{ml}$ of saline and the solution was used as sample for an assay. Activity of the sample solution was corresponded to $5 \mathrm{ng} / \mathrm{ml}$ of digoxin by an antidigoxin antibody test (the Enzymun-Test Digoxin, Boehringer Mannheim, FRG), and $\mathrm{Na}^{+}, \mathrm{K}^{+}-$ ATPase inhibitory activity was equivalent to that of $280 \mathrm{ng} / \mathrm{ml}$ of ouabain $\left(\mathrm{Na}^{+}, \mathrm{K}^{+}-\right.$ ATPase inhibitory activity was measured by the Fiske-Subbarow method developed in 1925). The active fraction was light brown syrup and relatively soluble in water. Since the fraction showed several peaks, it may contain a mixture of substances. However, we confirmed that the fraction had no contamination of catecholamines using the DEAE (basic)- and SP (acidic)- Sephadex.

Five mongrel dogs of either sex, weighing $6-17 \mathrm{~kg}$ were anesthetized with sodium pentobarbital $(30 \mathrm{mg} / \mathrm{kg}$, i.v.), and the dogs were sacrificed by rapid exsanguination from the right common carotid artery. The intermediate auricular artery of either ear was then carefully isolated and two or three segments (without large branches, $0.4-0.7 \mathrm{~mm}$ in outer diameter and 5-10 $\mathrm{mm}$ in length) were cut from each isolated artery. Each segment was carefully inserted by a stainless steel cannula with a small hole at $5 \mathrm{~mm}$ distance from the distal blind end (27 gauge, outer diameter of $0.4 \mathrm{~mm}$ and $3 \mathrm{~cm}$ in length). The isolated, cannulated artery was placed in a bath maintained at $37^{\circ} \mathrm{C}$ and perfused with $\mathrm{Krebs}$ solution by means of a peristaltic pump. The perfusion solution was bubbled with $95 \% \mathrm{O}_{2}$ and $5 \%$ $\mathrm{CO}_{2}$ which maintained the $\mathrm{pH}$ of the solution between 7.2-7.4. The flow rate $(0.5-1 \mathrm{ml} /$ $\min$ ) was initially adjusted so that the perfusion pressure was between $50-100 \mathrm{mmHg}$, subsequently the flow rate was kept constant throughout the experiments. The constrictor response was, therefore, observed as an increase in perfusion pressure. The details of the procedure were described in previous papers (Hongo and Chiba 1983; Ito and Chiba 1984).

\section{Results and Discussion}

When norepinephrine was injected intraluminally to the isolated intermediate auricular artery, strong vasoconstrictions were induced in a dose-related manner (increases in $105 \pm 15$ [mean \pm s.e. $] \mathrm{mmHg}$ at $0.01 \mu \mathrm{g}, n=5$ ). On the other hand, EDLF also induced transient vasoconstrictions in 5 used arterial preparations. Fig. 1 shows one of these vasoconstrictor responses to EDLF. The threshold dose of constrictions for inducing constrictions was approximately 1-3 $\mu 1$, and $10 \mu \mathrm{l}$ of EDLF usually induced a strong vasoconstriction [increases in $125 \pm 21$ (mean \pm s.E.) $\mathrm{mm} \mathrm{Hg}$ at $10 \mu l, n=5]$. The EDLF-induced vasoconstriction was reproducible at 10 -min intervals. The vasoconstriction induced by 0.1 $\mu \mathrm{g}$ of norepinephrine was completely inhibited by $10 \mu \mathrm{g}$ of phentolamine in two 


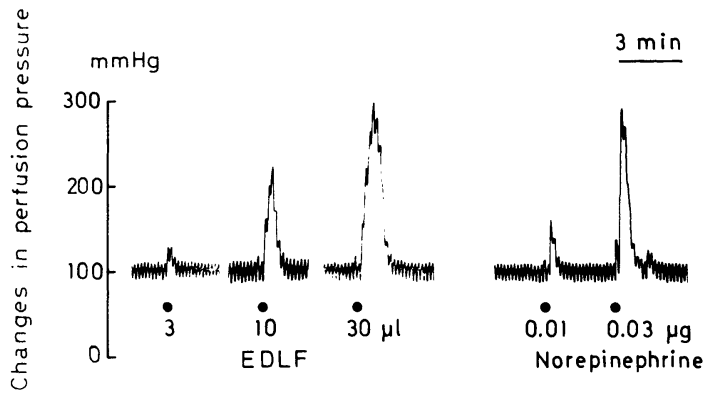

Fig. 1. Vasoconstrictor effects of increasing doses of endogenous digitalis-like factor (EDLF) and norepinephrine on an isolated, perfused dog intermediate auricular artery.

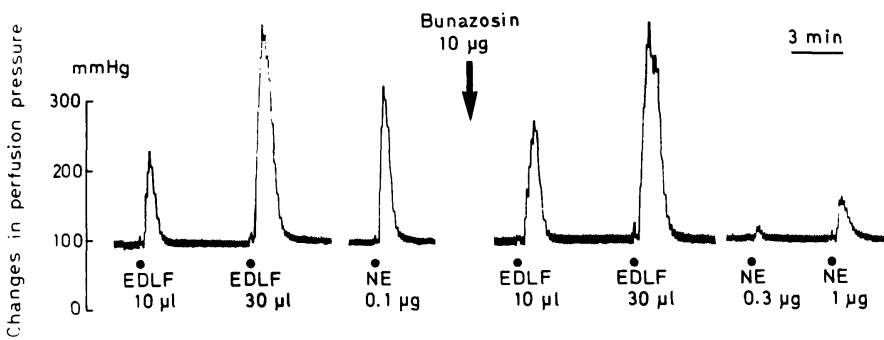

Fig. 2. Effects of $10 \mu \mathrm{g}$ of bunazosin on vasoconstrictions induced by 10 and 30 $\mu l$ of EDLF and norepinephrine (NE) in an isolated intermediate auricular artery.

experiments, but that by EDLF was not influenced by 10 and $100 \mu \mathrm{g}$ of phentolamine. Fig. 2 shows effects of $10 \mu \mathrm{g}$ of bunazosin, a potent alpha-1 adrenoceptor antagonist, on EDLF- and norepinephrine-induced vasoconstrictions. Bunazosin also markedly inhibited the norepinephrine-induced vasoconstriction but did not modify EDLF-induced constrictions.

As links between sodium pump inhibition and the increase in contractile force of heart muscle an increase in the intracellular calcium concentration transient following membrane excitation, the sequence being an increased intracellular $\mathrm{Na}^{+} / \mathrm{Ca}^{2+}$ exchange or, alternatively, a displacement of $\mathrm{Ca}^{2+}$ from membrane-associated $\mathrm{Ca}^{2+}$ pools are thought (Hansen 1984).

In the present experiments, we could demonstrate that EDLF caused a clear vasoconstriction in isolated, perfused intermediate auricular arteries of dogs. Since EDLF-induced vasoconstrictions were not influenced by alpha-adrenoceptor blockade in doses which completely blocked the norepinephrine-induced vasoconstrictor response, adrenergic mechanisms were not involved in the EDLF-induced vasoconstrictions. In the past, action of digitalis-like substances was not clear in vasculature. It may be due to different sensitivities of different regional vessels to such substances. In the present study, we used canine intermediate auricular arteries which distribute mostly to the skin. Thus, skin vessels may be sensitive 
to EDLF. However, as EDLF-induced vasoconstrictions were transient, there may be some differences in mechanism of action between EDLF and digitalis which induces longlasting vasoconstrictor responses (Higgins et al. 1972). In future, it is necessary to investigate the effects of EDLA on intracellular $\mathrm{Ca}^{2+}$ movements in the cardiac and vascular smooth muscles. Moreover, we need to perform a pharmacological analysis of the EDLF-induced vasoconstriction by use of pharmacologic key drugs like adrenoceptor, cholinoceptor antagonists, tetrodotoxin, calcium antagonist and so on, and to compare to effects of digitalis on vasculature.

\section{References}

1) Chakravarty, B., Mills, I.H. \& Callingham, B.A. (1984) Effects of natriuretic fractions of human urine on the isolated anococcygeus muscle of the rat. Renal Physiol., 7, 205-217.

2) Fiske, C.H. \& Subbarow, Y. (1925) The colorimetric determination of phosphorus. J. biol. Chem., 66, 375-400.

3) Hansen, O. (1984) Interaction of cardiac glycosides with $\left(\mathrm{Na}^{+}+\mathrm{K}^{+}\right)$-activated ATPase. A biochemical link to digitalis-induced inotropy. Pharmacol. Rev., 36, 143-163.

4) Higgins, C.B., Vatner, S.F. \& Braunwald, E. (1972) Regional hemodynamic effect of a digitalis glycosides in the conscious dog with and without experimental heart failure. Circulat. Res., 46, 406-417.

5) Hongo, K. \& Chiba, S. (1983) A new method for measuring vascular responsiveness of relatively larger arteries of dogs. $J$. pharmacol. Meth., 9, 83-91.

6) Ito, T. \& Chiba, S. (1984) Vascular responses of isolated canine intermediate auricular artery to vasoactive substances. Arch. int. Pharmacodyn., 268, 225-231.

7) Palluk R., Gaida, W. \& Hoefke, W. (1985) Atrial natriuretic factor. Life Sci., 36, 1415-1425.

8) Plunkett, W.C., Hutchins, P.M., Gruber, K.A. \& Buckalew, V.M., Jr. (1982) Evidence for a vascular sensitizing factor in plasma of saline loaded dogs. Hypertension, 4, 581-589.

9) Soldin, S.J. (1986) Digoxin-issues and contraversies. Clin. Chem., 32, 5-12. 